\title{
Integrated Services: \\ IP Networking Applications
}

\author{
Graham Howard \\ Siemens Internet Solutions \\ Siemens Public Communications Networks
}

Siemens Telecom Networks

900 Broken Sound Parkway

Boca Raton FL 33487

U.S. A.

Phone: $\quad+1(561) 955-8237$

Fax: $\quad+1$ (561) 955-6477

Email:_graham.howard@stn.siemens.com

Keywords

Internet, Applications, Convergence, Voice over IP, VoIP, Fax over IP, Middleware, Telecommunications,

\section{Extended Abstract}

\section{INTRODUCTION}

Many people have described the Internet and traditional telecommunications as being on a collision course, and portrayed these networks, and their respective operators and suppliers, as being mortal enemies.

In fact, these two networks are on a convergence path. With the great strengths of traditional circuit-switched, signalling system \#7 based, telecommunications, and computing / IP-based data, video and voice communications merging into a new, multifunctional, location independent, world-wide, seamless communications medium.

The original version of this chapter was revised: The copyright line was incorrect. This has been corrected. The Erratum to this chapter is available at DOI: 10.1007/978-0-387-35388-3_42 


\section{IP TELEPHONY DRIVING FORCES - ECONOMICS NOT TECHNOLOGY}

It is important to understand that IP telephony is not a new technology in search of a customer. It is a clear response to intense market, regulatory and competitive pressures, which are examined in detail. This includes a review of current industry value chains, the re-regulation of the communications industry, and the availability of new, low-cost technical solutions to these challenges. The importance of end-user acceptance as a key criterion is also examined.

The new telecommunications environment will thus consist of new value chains, new challenges and opportunities for existing carriers and new opportunities for second-generation carriers. These are also described in detail, with special emphasis on IP telephony as the key enabling technology.

\section{IP TELEPHONY - REQUIREMENTS FOR TRUE CARRIER GRADE}

Many people have confused IP Telephony with simple VoIP gateways. The paper includes a detailed review of the architecture of an IP Telephony system, and describes all the elements required for a true carrier-grade solution - which demonstrates it is far more than just providing gateways.

\section{ADVANCED IP TELEPHONY NETWORK SERVICES}

IP Telephony is thus a solution that addresses increasing competition, re-regulation and customer needs. It enables new service combinations, including telephony, data, networking, video, high-quality audio, multimedia messaging, electronic commerce, call centers, service centers, web / PSTN integration, and a myriad of other services. It is these that will drive IP telephony, not just cheaper POTS (Plain Old Telephone Service), and all are described in detail.

\section{THE IMPORTANCE OF SS\#7 AND AIN}

Much of the existing world telecommunications infrastructure is based on SS\#7. Bridging this world with the IP world is key to efficient network integration. The interaction of SS\#7 and IP is examined, and illustrated by examples of some of the innovative services it can provide.

AIN (Advanced Intelligent Networks) is also an essential component, because it enables new and existing service providers to rapidly deploy advanced services, using the transport mechanisms, without having to embed large amounts of call-processing software in the network elements themselves.

The interaction of AIN and Web based features will provide the most innovative service combinations. 


\section{MANAGEMENT AND BILLING FOR THE NEW SERVICES}

Contrary to popular belief, VoIP is not free - it includes sophisticated requirements for the support of both owned-network and wholesale / retail business models, as well as location independent services, global availability, bundled service packages etc. These requirements are described, as well as some of the business models they support.

\section{CUSTOMERS AND SERVICES ARE THE KEYS}

Who provides the best and most responsive services - and thus who builds and retains the largest customer base, is therefore the real measure of success.

In a truly global, IP based, communications market, the services can be provided from anywhere. Ownership of the network elements and network infrastructure, and provision of the services to customers, are therefore independent in this new communications environment.

\section{INTEGRATED SERVICES: IP NETWORKING APPLICATIONS}

The paper will conclude with an up-to-the-minute review of key industry trends, network plans and deployments and results of early service experience:

\section{Full Paper}

A full text of this paper will be provided at the Conference.

\section{BIOGRAPHY}

Graham Howard is currently Manager of Advanced Applications Implementation in the Siemens Internet Solutions Business Unit..

Previously he was responsible for New Product Development for Siemens Telecom Networks. Products included extensive work in Wireless systems, especially Personal Communications Services (PCS), knowledge based systems, Internet, SONET, Digital Loop Carrier, Fiber-inthe-Loop, and ISDN CPE.

Mr. Howard has extensive international experience in all branches of telecommunications, and was previously the Product Planning Executive for GPT in the United Kingdom, where he was also active in the IEE (Institution of Electrical Engineers), and lectured at several Universities. 